\title{
Commentary: Engrailed 1 Shapes the Dopaminergic and Serotonergic Landscape through Proper IsO Maintenance and Function
}

\author{
Willemieke M. Kouwenhoven and Marten P. Smidt
}

Swammerdam Institute for Life Sciences, University of Amsterdam, Amsterdam, the Netherlands

Article Info

\section{Article Notes}

Received: June 17, 2016

Accepted: August 01, 2016

\section{${ }^{*}$ Correspondence:}

Dr. Marten P. Smidt

Swammerdam Institute for Life Sciences

University of Amsterdam, P.O. Box 94215

1090 GE Amsterdam, The Netherlands

Email: m.p.smidt@uva.nl

c 2016 Smidt MP. This article is distributed under the terms of the Creative Commons Attribution 4.0 International License

\section{Keywords}

Engrailed 1

IsO

mdDA neurons

Mouse

\section{ABSTRACT}

Two essential monoaminergic neurotransmitter systems are located within the midbrain and the hindbrain region: the mesodiencephalic dopaminergic (mdDA) neurons, which can be divided in the substantia nigra (SN), the ventral tegmental area (VTA), and the serotonergic (5-HT) neurons. In the adult brain these two types of monoaminergic neurons are critical to our neurological health. Dysfunction of the mdDA system has been associated with schizophrenia and Parkinson's Disease (PD), while dysfunction of the 5HT system has in turn been associated with psychiatric diseases such as depression and autism. The homeobox transcription factor Engrailed 1 (En1) is expressed in both types monoaminergic neurons, and is required for the correct programming and survival of the MdDA and 5HT neurons. Recently, we reported on the dual role of En1 in both neurotransmitter systems through its central role in the maintenance of the Isthmic Organizer, which is the embryonic signaling center that instructs and separates dopaminergic and serotonergic neuronal development.

\section{Introduction}

The midbrain and hindbrain are separated from each other during embryogenesis by the isthmic organizor (IsO). The location of the IsO is determined by the boundary between the expression of homeobox transcription factors Otx2 and Gbx2 ${ }^{1-4}$. The IsO is formed at $\sim$ E7-8 of murine embryonic development and is characterized by the expression of fibroblast growth factor 8 (Fgf8) ${ }^{5}$ and secreted glycoprotein $\mathrm{Wnt}^{6}{ }^{6}$. The IsO functions as a signaling center that pushes the development of mesodiencephalic dopaminergic neurons (mdDA) in the midbrain, and the development of serotonergic (5HT) neurons in the hindbrain.

Engrailed 1 is a homeobox transcription factor that is highly conserved amongst species ${ }^{7}$, and is expressed in both types of monoaminergic neurons ${ }^{8-11}$. Moreover, lineage trace studies showed that En1-derived cells are present in di-, mes- and metencephalon ${ }^{12,13}$. En1 is required for the survival of both $5 \mathrm{HT}$ neurons ${ }^{14}$, and mdDA neurons: severe phenotypical changes are present in the mdDA system of the En1-homozygous mouse ${ }^{15}$. Moreover, animals heterozygous for En1 are considered as a model for Parkinson's Disease, as they show progressive cell loss ${ }^{16-18}$.

\section{En1 is Required for the Correct Function of the IsO}

The authors of the discussed work continued the investigation of the En1-ablated animals ${ }^{19}$, as they had observed additional changes in the mid- and hindbrain of En1-ablated animals 
(that had been only briefly described ${ }^{15}$ ). Using an elaborate number of En1-ablated mutant mouse models (En1Cre;YFP, En1K0;Pitx3GFP/GFP and En1BatGal) the authors report that the expression patterns of mesencephalic Nurr1-targets (i.e. dopaminergic genes such as Th and Dat) are caudally extended into the hindbrain. The authors describe the presence of these ectopic dopaminergic (eDA) neurons both in embryonic and adult En1-ablated brains, and reveal that they arise at the expense of rostral 5HT neurons. Moreover, it is established that the (intrinsic) electrophysiological profile of the eDA neurons was indistinguishable from control mdDA neurons, using an En1-ablated model in which the mdDA and eDA neurons could be selectively visualized and studied, using GFP under the promotor of Pitx3. The authors continue to show that these changes are the result of aberrant expression and maintenance of the IsO, the developmental border between the midand hindbrain. This was visualized by aberrant and more caudally located expression patterns of important Is0-determinants such as Wnt1, Otx2, and Fgf8. Similar alterations in IsO maintenance were reported for $\mathrm{Gbx} 2$ ablated mice $^{4}$, as well as Wnt1- and Otx2-over-expression mice (using the En1 expression locus) ${ }^{20,21}$. Additionally, the authors draw a comparison to the known role of En1 in the formation of the apical ectodermal ridge (AER), which is the signaling center required for hindlimb formation $^{22}$. Similar to the IsO, the AER is characterized by a single band of Fgf8 expression that separates the dorsal from the ventral hindlimb ${ }^{23}$. En 1 contributes to the maintenance of this boundary, since En1-ablated animals display aberrant Fgf8 expression and an extension of the dorsal hindlimb fate into the ventral side ${ }^{22,24,25}$.

The authors thus make a strong case for a dual, pivotal role of En1 in the mid-hindbrain region: En1's presence is required for the cell survival of both mdDA and the 5HT neurons, as well as for the correct function and maintenance of the IsO.

\section{Strong Similarity between Midbrain and Rostral Hindbrain require Robust Division}

It is easy to imagine the mid-hindbrain region as two very distinct and unique (i.e. dopaminergic and serotonergic) landscapes divided by the IsO. The opposing expression of Otx 2 and Gbx2 form and underline the pivotal differences between the mid- and hindbrain ${ }^{1-6}$. However, these classic IsO studies also revealed the plasticity and the similarities of the midbrain and rostral hindbrain region, as slight genetic manipulations are enough to introduce ectopic dopaminergic or serotonergic neurons ${ }^{19-21,26}$. The hindbrain can be divided into twelve rhombomeres, and the first segment can be separated in the isthmus (R0), rostral R1 (R1r) and caudal R1 (R1c) ${ }^{27}$. The patterning of the hindbrain rhombomeres is beautifully orchestrated by the Hox-code: a cluster of genes that program the rostralcaudal axis, and whose location on the genome and time of expression corresponds to that rostral-caudal axis ${ }^{28}$. Interestingly, the Hox-code starts at the R1-R2 boundary with the expression of Hoxa $2^{29}$, leaving R1 (similar to the midbrain) devoid of Hox gene expression.

The kinship between the midbrain-R1 region is further established by the tracing studies which reveal that the cells in the mesencephalon and R1 trace back to the same En1-positive lineage ${ }^{19}$, which was equally reported by other groups ${ }^{12,13}$. Moreover, a short-term reaggregation assay illustrated that distinctly-labeled cells from chick midbrain and R1, when mixed together, are prone to remain mixed ${ }^{30}$. The absence of segregation behavior was mimicked by the isolated chick cells from non-adjacent rhombomeres (either odd- or evennumbered rhombomeres). In contrast, when cells from adjacent rhombomeres were mixed together, the cells would segregate ${ }^{30,31}$. It was shown that adjacent rhombomeres maintain cellular segregation of the different rhombomeric segments through the activity of Ca2+-dependent adhesion molecules ${ }^{31}$. This thus suggests that midbrain and $\mathrm{R} 1$ possess similar adhesive qualities, and do not intrinsically segregate from each other.

Taken together, the strong resemblance between the embryonic midbrain and R1 underlines the necessity of a signaling center that enables these two regions to each develop their own distinct monoaminergic fate. The data from the discussed work clearly establish that En1 plays a pivotal role in this process.

\section{Future Directions and Neurological Implications}

The neurogenetic similarities between the embryonic midbrain and R1, as well as their common En1-positive lineage also lead to the question: how does -during normal wild-type development- En1 promote dopaminergic differentiation in the midbrain, but repress this cell fate in R1? The authors of the discussed work raise this question, and while providing two theoretical possibilities, fail to provide molecular evidence. The authors first propose a differential interaction between En1 and members of the Pbx family, as research in drosophila has shown that presence of Exd (a Pbx orthologue) can divert the repressive effect of En1 on its targets into an activation of its targets ${ }^{7}$. Secondly, the authors hypothesize that En1 binds an enhancer region in the 0tx2 locus to repress Otx2 expression in R1 (similar to $\mathrm{Gbx} 2$ ), but loses the competition to bind this region to $\operatorname{Brn} 1 / 2 / 4$ and Oct6, which are differentially expressed in the midbrain ${ }^{19,32-34}$. Future studies should test these hypotheses, to expand our understanding of the development of mid-hindbrain region. These data might not only contribute to our understanding of the molecular programming of mdDA and 5HT neurons, and fundamental IsO-development, but may also provide genetic leads to understand the aetiology of neurological malformations of the mid- and hindbrain in adult patients ${ }^{35}$. 


\section{References}

1. Broccoli V, Boncinelli E, Wurst W. The caudal limit of Otx2 expression positions the isthmic organizer. Nature. 1999;401(6749):164-8.

2. Martinez S, Crossley PH, Cobos I, Rubenstein JL, Martin GR FGF8 induces formation of an ectopic isthmic organizer and isthmocerebellar development via a repressive effect on Otx2 expression. Development. 1999;126(6):1189-200.

3. Millet S, Campbell K, Epstein DJ, Losos K, Harris E, Joyner AL. A role for Gbx2 in repression of Otx2 and positioning the mid/hindbrain organizer. Nature. 1999;401(6749):161-4.

4. Wassarman KM, Lewandoski M, Campbell K, Joyner AL, Rubenstein JL, Martinez S, et al. Specification of the anterior hindbrain and establishment of a normal mid/hindbrain organizer is dependent on Gbx2 gene function. Development. 1997;124(15):2923-34.

5. Crossley PH, Martin GR. The mouse Fgf8 gene encodes a family of polypeptides and is expressed in regions that direct outgrowth and patterning in the developing embryo. Development. 1995;121(2):43951.

6. Wilkinson DG, Bailes JA, Mcmahon AP. Expression of the protooncogene int-1 is restricted to specific neural cells in the developing mouse embryo. Cell. 1987;50(1):79-88.

7. Serrano N, Maschat F. Molecular mechanism of polyhomeotic activation by Engrailed. EMBO J. 1998;17(13):3704-13.

8. Deneris ES, Wyler SC. Serotonergic transcriptional networks and potential importance to mental health. Nat Neurosci. 2012;15(4):51927

9. Lundell MJ, Chu-lagraff Q, Doe CQ Hirsh J. The engrailed and huckebein genes are essential for development of serotonin neurons in the Drosophila CNS. Mol Cell Neurosci. 1996;7(1):46-61.

10. Simon HH, Scholz C, O'leary DD. Engrailed genes control developmental fate of serotonergic and noradrenergic neurons in mid- and hindbrain in a gene dose-dependent manner. Mol Cell Neurosci. 2005;28(1):96105.

11. Veenvliet JV, Smidt MP. Molecular mechanisms of dopaminergic subset specification: fundamental aspects and clinical perspectives. Cell Mol Life Sci. 2014;71(24):4703-27.

12. Yang J, Brown A, Ellisor D, Paul E, Hagan N, Zervas M. Dynamic temporal requirement of Wnt1 in midbrain dopamine neuron development. Development. 2013;140(6):1342-52.

13. Zervas M, Millet S, Ahn S, Joyner AL. Cell behaviors and genetic lineages of the mesencephalon and rhombomere 1. Neuron. 2004;43(3):34557.

14. Fox SR, Deneris ES. Engrailed is required in maturing serotonin neurons to regulate the cytoarchitecture and survival of the dorsal raphe nucleus. J Neurosci. 2012;32(23):7832-42.

15. Veenvliet JV, Dos Santos MT, Kouwenhoven WM, von Oerthel L, Lim JL, van der Linden AJ, et al. Specification of dopaminergic subsets involves interplay of En1 and Pitx3. Development. 2013;140(16):3373-84.

16. Albéri L, Sgadò P, Simon HH. Engrailed genes are cell-autonomously required to prevent apoptosis in mesencephalic dopaminergic neurons. Development. 2004;131(13):3229-36.

17. Sgadò P, Albéri L, Gherbassi D, Galasso SL, Ramakers GM, Alavian $\mathrm{KN}$, et al. Slow progressive degeneration of nigral dopaminergic neurons in postnatal Engrailed mutant mice. Proc Natl Acad Sci USA. 2006;103(41):15242-7.

18. Le Pen G, Sonnier L, Hartmann A, Bizot JC, Trovero F, Krebs MO, et al. Progressive loss of dopaminergic neurons in the ventral midbrain of adult mice heterozygote for Engrailed1: a new genetic model for Parkinson's disease?. Parkinsonism Relat Disord. 2008;14 Suppl 2:S107-11.

19. Kouwenhoven WM, Veenvliet JV, Van hooft JA, Van der heide LP, Smidt MP. Engrailed 1 shapes the dopaminergic and serotonergic landscape through proper isthmic organizer maintenance and function. Biol Open. 2016;5(3):279-88.

20. Brodski C1, Weisenhorn DM, Signore M, Sillaber I, Oesterheld M, Broccoli $\mathrm{V}$, et al. Location and size of dopaminergic and serotonergic cell populations are controlled by the position of the midbrainhindbrain organizer. J Neurosci. 2003;23(10):4199-207.

21. Prakash N, Brodski C, Naserke T, Puelles E, Gogoi R, Hall A, et al. A Wnt1regulated genetic network controls the identity and fate of midbraindopaminergic progenitors in vivo. Development. 2006;133(1):89-98.

22. Adamska M, Macdonald BT, Sarmast ZH, Oliver ER, Meisler MH. En1 and Wnt7a interact with Dkk1 during limb development in the mouse. Dev Biol. 2004;272(1):134-44.

23. Moon AM, Capecchi MR. Fgf8 is required for outgrowth and patterning of the limbs. Nat Genet. 2000;26(4):455-9.

24. Cygan JA, Johnson RL, Mcmahon AP. Novel regulatory interactions revealed by studies of murine limb pattern in Wnt-7a and En-1 mutants. Development. 1997;124(24):5021-32.

25. Loomis CA, Kimmel RA, Tong CX, Michaud J, Joyner AL. Analysis of the genetic pathway leading to formation of ectopic apical ectodermal ridges in mouse Engrailed-1 mutant limbs. Development. 1998;125(6):1137-48.

26. Vernay B, Koch M, Vaccarino F, Briscoe J, Simeone A, Kageyama R, et al. Otx2 regulates subtype specification and neurogenesis in the midbrain. J Neurosci. 2005;25(19):4856-67.

27. Alonso A, Merchán P, Sandoval JE, Sánchez-Arrones L, Garcia-Cazorla A, Artuch R, et al. Development of the serotonergic cells in murine raphe nuclei and their relations with rhombomeric domains. Brain Struct Funct. 2013;218(5):1229-77.

28. Parker HJ, Bronner ME, Krumlauf R. The vertebrate Hox gene regulatory network for hindbrain segmentation: Evolution and diversification: Coupling of a Hox gene regulatory network to hindbrain segmentation is an ancient trait originating at the base of vertebrates. Bioessays. 2016;38(6):526-38.

29. Gavalas A, Davenne M, Lumsden A, Chambon P, Rijli FM. Role of Hoxa2 in axon pathfinding and rostral hindbrain patterning. Development. 1997;124(19):3693-702.

30. Jungbluth S, Larsen C, Wizenmann A, Lumsden A. Cell mixing between the embryonic midbrain and hindbrain. Curr Biol. 2001;11(3):204-7.

31. Wizenmann A, Lumsden A. Segregation of rhombomeres by differential chemoaffinity. Mol Cell Neurosci. 1997;9(5-6):448-59.

32. Inoue F, Kurokawa D, Takahashi M, Aizawa S. Gbx2 directly restricts Otx2 expression to forebrain and midbrain, competing with class III POU factors. Mol Cell Biol. 2012;32(13):2618-27.

33. Kurokawa D, Kiyonari H, Nakayama R, Kimura-yoshida C, Matsuo I, Aizawa S. Regulation of Otx2 expression and its functions in mouse forebrain and midbrain. Development. 2004;131(14):3319-31.

34. Kurokawa D, Takasaki N, Kiyonari H, et al. Regulation of Otx2 expression and its functions in mouse epiblast and anterior neuroectoderm. Development. 2004;131(14):3307-17.

35. Barkovich AJ. Developmental disorders of the midbrain and hindbrain. Front Neuroanat. 2012;6:7. 